\title{
DEVELOPMENT OF THE OZONIZER AND OZONATION TECHNOLOGY FOR WATERWORKS IN JAPAN
}

\author{
Hiroshi HOSHIKAWA*, Takayuki MORIOKA*, Shigeru HATSUMATA* \\ * Fuji Electric Systems Co., Ltd., 11-2 Osaki 1-chome, Shinagawa-ku, \\ Tokyo 141-0032、Japan
}

\begin{abstract}
Advanced water treatment facilities are used widely, mainly to remove taste and odor and to reduce trihalomethane generation. Each such facility consists of an ozonation and biological activated carbon (BAC) process and has made the achievement in wateworks (Sato, 2002). To make these facilities more efficient, a large number of researchers were taken to make the ozonizer more efficient and to enhance treatment technology. The ozonizer was reduced in the discharge gap using oxygen, and thus increasing ozone concentrations to $300 \mathrm{~g} / \mathrm{Nm}^{3}$. However, to avoid incomplete combustion and ensure safety, ozone concentrations must be within $150 \mathrm{~g} / \mathrm{Nm}^{3}$ (Ishioka, 2002; Mizutani et al., 1999).

The present report also demonstrates that ozonation technology is effective in removing taste and odor and in reducing trihalomethane ( Morioka et al., 1993; Morioka, 2001); and that bromate information can be suppressed by keeping concentrations of dissolved ozone to no more than $0.1 \mathrm{mg} / \mathrm{L}$ ( Kato et al 2002).

To spread and establish ozonation more widely, basic research with demonstrative plants must be conducted with regard to ozonation techniques that are capable of handling raw water from waterworks.
\end{abstract}

\section{KEYWORDS}

Ozonation; ozonizer; Silent discharge method; Biological activated carbon(BAC); Trihalomethane; Bromate

\section{INTRODUCTION}

Waterworks sources in the largest cities are highly contaminated, and advanced water treatment facilities have been introduced, with favorable results, to remove taste and odor and to reduce trihalomethane that cannot be treated with conventional techniques of water purification. Advanced water treatment facilities consist mainly of ozonation and biological activated carbon (BAC) treatment. Ozone has powerful oxidation capability, and is thus able to treat both of them. However, for highly efficient treatment, it is important to increase ozone generation efficiency and to cause necessary and sufficient oxidation reactions in ozone contact basins.

Following the introduction of ozonation, new challenges have appeared such as information of bromate by ozonation and inactivation of cryptosporidium. These must also be solved.

The present report addresses these issues, together with techniques to solve those 
problems, and classifies them into ozonizer (which is the key hardware in advanced water treatment facilities) and ozonation techniques. The report then describes the recent status of each of the issues.

\section{RESEARCH AND DEVELOPMENT IN INCREASING OZONE CONCENTRATION}

\section{Ozone generation Method and scale of use}

Table 1 summarizes the ozone generation method and their scales of use.

Table 1. Processes for ozone generation and their scales of use

\begin{tabular}{|c|c|c|c|c|}
\hline Item & UV irradiation & Electrolysis & Silent discharge & Utility \\
\hline$<0.1 \mathrm{~kg} / \mathrm{h}$ & $\bigcirc$ & $\bigcirc$ & $\bigcirc$ & $\begin{array}{c}\text { Laboratory } \\
\text { Pool }\end{array}$ \\
\hline $0.1 \sim 1 \mathrm{~kg} / \mathrm{h}$ & & $\bigcirc$ & $\bigcirc$ & $\begin{array}{c}\text { Wastewater } \\
\text { Night soil }\end{array}$ \\
\hline $1 \mathrm{~kg} / \mathrm{h}<$ & & & $\bigcirc$ & $\begin{array}{c}\text { Drinking water } \\
\text { Sewage water }\end{array}$ \\
\hline
\end{tabular}

Ozone can be produced by ultraviolet irradiation, electrolysis, and silent discharge methods. The appropriate method is selected according to the objective and scale of use. To produce a stable supply of ozone efficiently at industrial scales, the silent discharge method is proven to be the most effective.

\section{Principles of ozone generation using the silent discharge method}

Air or oxygen is used as the raw material gas. One or both of the main electrodes are covered with glass or other dielectric. An alternating current high voltage (about $10 \mathrm{kV}$ ) is applied between the main electrodes to generate ozone.

\section{Factors that determine the generation efficiency of ozone}

The three factors outlined below determine the efficiency of ozone generation.

\section{Discharge gap length}

The shorter the discharge gap, the higher the ozone concentration is generated. Currently, discharge gap of ozone generation pipes is about $1 \mathrm{~mm}$. However, manufacturing technology has recently progressed, so that discharge gap about $0.3 \mathrm{~mm}$ can now be produced, resulting in higher efficiency.

\section{Power density}

It is natural that an increase in power density will result in an increase in ozone 
concentration. However, at rates of up to 160 watts $\mathrm{min} / \mathrm{L}$, ozone concentration increases linearly with power density. At rates higher than this, ozone concentration become saturated.

\section{Oxygen concentration of raw gas}

The higher the concentration of oxygen in the raw material gas, will result in an increase in ozone concentration. To increase ozone concentration, therefore, it is advised to use oxygen instead of air.

\section{High concentration ozonizer}

The original principles of ozone generation have not changed. As a result of a wide spectrum of research and development, ozone concentrations of ozonizers have increased 15-fold from $20 \mathrm{~g} / \mathrm{Nm}^{3}$ to $300 \mathrm{~g} / \mathrm{Nm}^{3}$ and are being put to practical use one by one.

Table 2 compares the performance of conventional ozonizers with that of current ones.

Table 2. Performance of high-concentration ozonizers

\begin{tabular}{|c|c|c|}
\hline Item & Ordinary concentration & High concentration \\
\hline Method & Silent discharge & Silent discharge \\
\hline Discharge gap & $1.0 \mathrm{~mm}$ & $0.3 \mathrm{~mm}$ \\
\hline Power density & $20 \mathrm{watt} \mathrm{min} / \mathrm{L}$ & $300 \mathrm{watt} \mathrm{min} / \mathrm{L}$ \\
\hline Oxygen concentration & $20 \mathrm{Vol} . \%$ & $100 \mathrm{Vol} . \%$ \\
\hline Ozone concentration & $20 \mathrm{~g} / \mathrm{Nm}^{3}$ & $300 \mathrm{~g} / \mathrm{Nm}^{3}$ \\
\hline
\end{tabular}

However, in high concentrations, ozone decomposes and burns during heating and increases in pressure. Ozone users must therefore ensure adequate safety. It is used the technique to evaluate explosions of combustible mixed gases and examined the decomposition combustion characteristics of high-concentration ozone. The experiment conditions were as follows:
raw material gas,
oxygen
source of ignition,
red-hot nichrome wire
ignition energy,
$60 \mathrm{~J}$
container volume,
$0.98 \mathrm{~L}$
ozone gas pressure
$0.1 \mathrm{MPa}$ to $1.6 \mathrm{MPa}$.
in the container,

The results are shown in Fig. 1. Here, ozone decomposition is defined as follows:

Ozone decomposition ratio $(\%)=($ initial ozone concentration - decomposed ozone concentration) / (initial ozone concentration). 
As is evident from Fig.1, ozone decomposition is zero when the ozone concentration is about $150 \mathrm{~g} / \mathrm{Nm}^{3}$ or less. However, above this, decomposition increases rapidly. When ozone concentration reaches $250 \mathrm{~g} / \mathrm{Nm}^{3}$ or greater, decomposition is $100 \%$. The same trend was shown regardless of the initial gas pressure. This led to the conclusion that concentrations of ozone should be kept within $150 \mathrm{~g} / \mathrm{Nm}^{3}$ in order to safely manage high-concentration ozone.

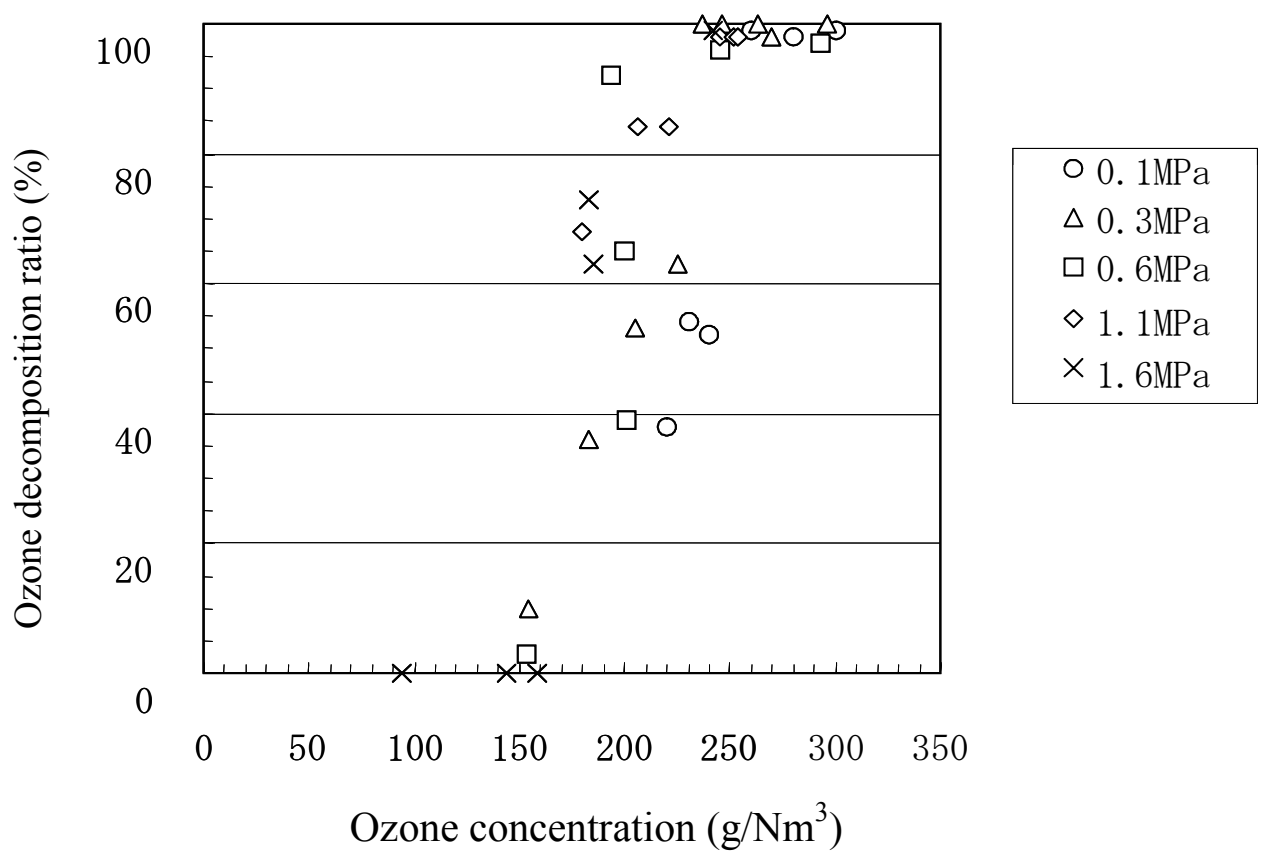

Fig. 1. Ozone concentration and decomposition

\section{RESEARCH AND DEVELOPMENT IN OZONATION TECHNOLOGY}

\section{Objectives of ozonation}

The main objectives of ozonation are to reduce trihalomethane and to remove taste and odor. These taste and odor present in Japan waterworks are caused by geosmin (water quality regulation, $0.01 \mu \mathrm{g} / \mathrm{L}$ ) and 2-methylisoborneol (water quality regulation , 0.01 $\mu \mathrm{g} / \mathrm{L}$ ), which are the metabolic products of actinomycetes and cyanobacteria. these compounds cannot be removed sufficiently with conventional water treatment systems. Ozonation is considered to be one of the most promising processes for coping with undesirable odors in municipal water supplies in Japan.

\section{Situation of introduction of advanced water treatment facilities}

The first advanced water treatment facilities was introduced to Japan in the 1970s. Japan, therefore, has only a short history compared with Europe and U.S.A. Such systems were actively introduced to Tokyo, Osaka, and other large cities where water sources are highly contaminated. These systems have been spread and established mainly in such areas. Throughout Japan, the quantity of raw water to be treated by such facilities established so far has reached about 9 million cubic meters per day in Japan. 


\section{Ozone oxidation reactions}

Ozone oxidation reactions can be roughly divided into direct and indirect reactions. A direct reaction is a reaction with molecular ozone $\left(\mathrm{O}_{3}\right)$ itself. An indirect reaction is a reaction of the hydroxyl radical $(\cdot \mathrm{OH})$ generated by self-decomposition of ozone. Most reactions of ozone with 2-methylisoborneol or geosmin, which are found to be causes of water taste and odor, are radical reactions. Figure 2 shows an ozone reaction model extended by the coauthors (Morioka et al., 1994) from the self-decomposition model

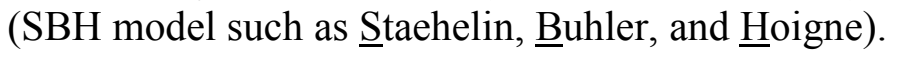

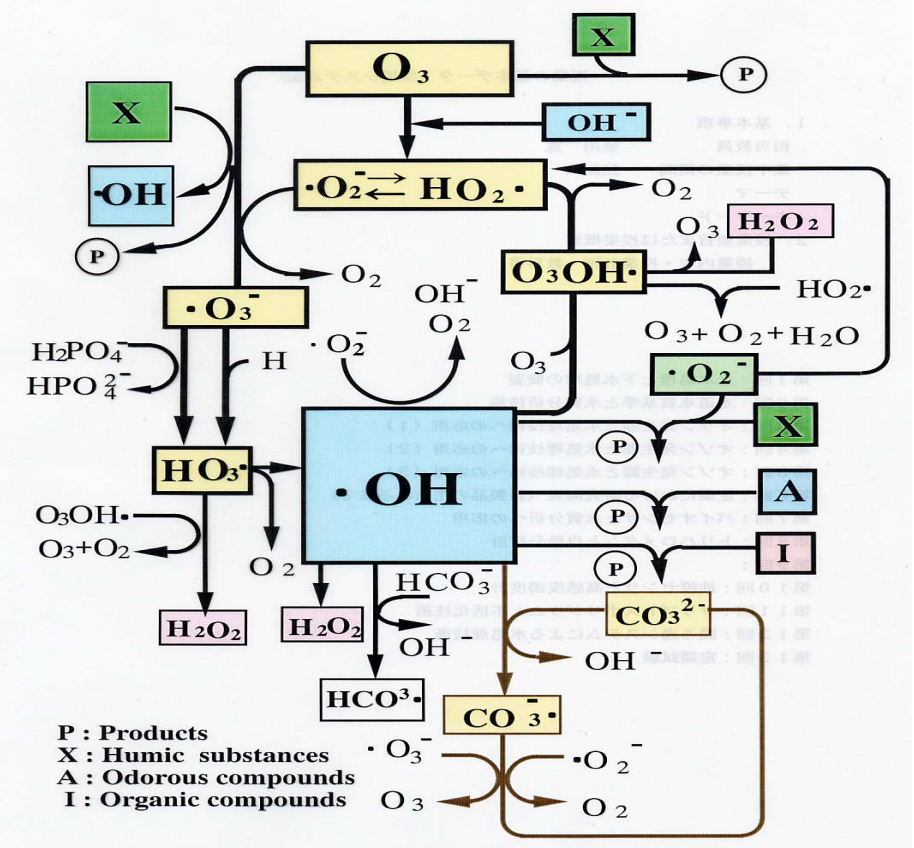

Fig. 2. Schematic diagram of an extended SBH model

\section{Effects of introduction of advanced water treatment facilities}

The advanced water treatment facilities has proven effective in removing taste and odor and reducing trihalomethane from water, along with other effects. The Kanamachi Purification Plant of Tokyo, for example, introduced facilities (ozonation and BAC) with a capacity of $260,000 \mathrm{~m}^{3} /$ day in 1992 and 1996. The facilities has since been running in good condition. The effects of these are reported (Sato, 2002) as follows:

1) 2-methylisoborneol is removed at a rate of about $70 \%$ by ozonation and entirely by BAC treatment.

2) BAS is removed by about $35 \%$ by ozonation and about $80 \%$ in all processes.

3) Ammonia is not removed by ozonation, but most of it is removed by BAC treatment.

4) THMFP is removed by $10 \%$ by ozonation and about $60 \%$ in all processes. 


\section{Inactivation of cryptosporidium parvum by ozone}

In 1994, some 400,000 people became infected with cryptosporidium parvum and 400 people died in the United States. In Japan, 8,800 people became infected in Saitama Prefecture in 1996, and it was recognized as becoming a big problem in society.

Cryptosporidium parvum, as shown in Fig. 3, is about $5-\mu \mathrm{m}$ in diameter. To cannot treate the cryptosporidium parvum by chlorine disinfection, the turbidity at the exit of the sand filtration basin is set to a turbidity of 0.1 degrees or less. However, this method is neither safe nor appropriate.

Ozonation has always been known to be an effective technique for disinfection. However, it involves different processes, each of which has different experimental conditions, methods of evaluation, and other factors, so that there are large dispersions in values of CT (C, concentrationof dissolved ozone in $\mathrm{mg} / \mathrm{L}$; and $\mathrm{T}$, contact time in minutes). Studies carried out by the coauthors indicate that the CT value required for $90 \%$ inactivation is $7.1 \mathrm{mg} . \mathrm{min} / \mathrm{L}$ on average, with a range of 6.3 to $7.6 \mathrm{mg} / \mathrm{min} / \mathrm{L}$, at $\mathrm{pH} 7.1,20^{\circ} \mathrm{C}$, and at a concentration of initial Cryptosporidium parvum of $10^{5}$ pieces $/ \mathrm{mL}$. For $99 \%$ inactivation, an average of $12 \mathrm{mg} \cdot \mathrm{min} / \mathrm{L}$, and in the range of 10 to $12 \mathrm{mg} . \mathrm{min} / \mathrm{L}$, is required. These values can be classed as practical.

\section{Technique for suppressing bromate formation}

The ozonation of raw water containing bromide ions leads formation of the by-product bromate as shown in Fig. 4 ( Hagg et al., 1983; Von, Gunten et al 1994 ; Von, Gunten et al 1998). Bromates has been classified as a group 2B carcinogens, by the International Cancer Research Organization ( IARC), and maximum value of $0.025 \mathrm{mg} / \mathrm{L}$ was recommended in 1993 by the World Health Organization ( WHO ).

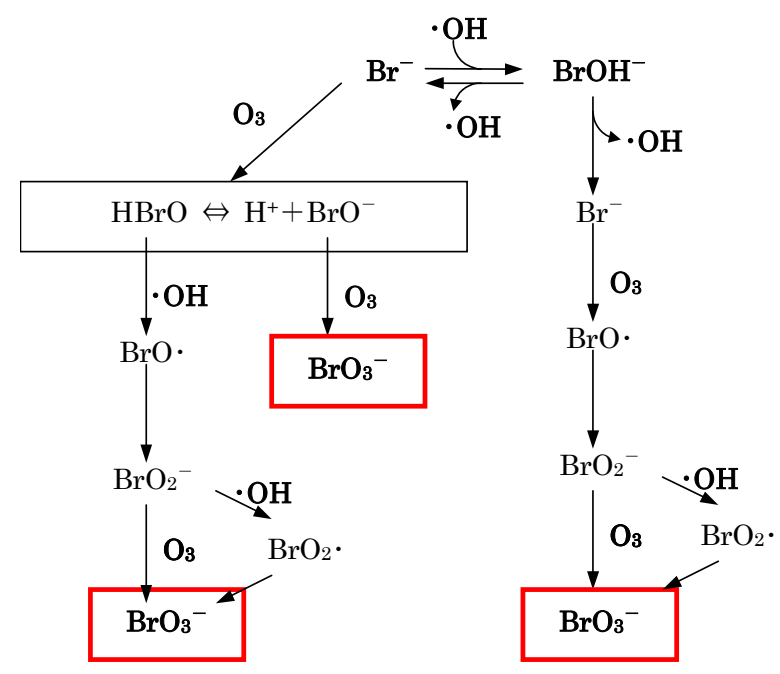

Fig. 4. Mechanism for bromate formation 
New water quality standards for drinking water to be enforced in April 2004 indicates a standards value of $0.01 \mathrm{mg} / \mathrm{L}$ in Japan. An appropriate treatment must therefore be applied to maintain bromate value below this standards value.

Bromate formation with ozone was investigated to obtain an indicator of ozone injection control. Raw water were collected from the Tama and the Edo Rivers in Japan . Figure 5 shows the results obtained when raw water from the Tama River was used. Figure 6 shows the results obtained when raw water from the Edo River was used. Upon comparison, the two were shown to have identical trends. That is, applying ozone causes ozone first to oxidize and consume in-water substances to be oxidized, with no dissolved ozone being detected. However, when dissolved ozone is detected, the generation of bromates will increase with a rise in concentration. If the concentration of bromine ions is low, the concentration of bromates to be generated will obviously decrease.

As a result, bromate concentration can be controlled by controlling the concentrations of dissolved ozone. If the raw water is from the Tama River, as shown in Fig. 5, it is sufficient to maintain the concentration of dissolved ozone at $0.17 \mathrm{mg} / \mathrm{L}$ to maintain the bromate concentration standard of $0.01 \mathrm{mg} / \mathrm{L}$. Similarly, if raw water from the Edo River, as shown in Fig. 6 is used, it is sufficient to maintain a comparable concentration at $0.25 \mathrm{mg} / \mathrm{L}$ or less. In practice, it is appropriate to maintain the concentration of dissolved ozone at $0.1 \mathrm{mg} / \mathrm{L}$ while ensuring safety.
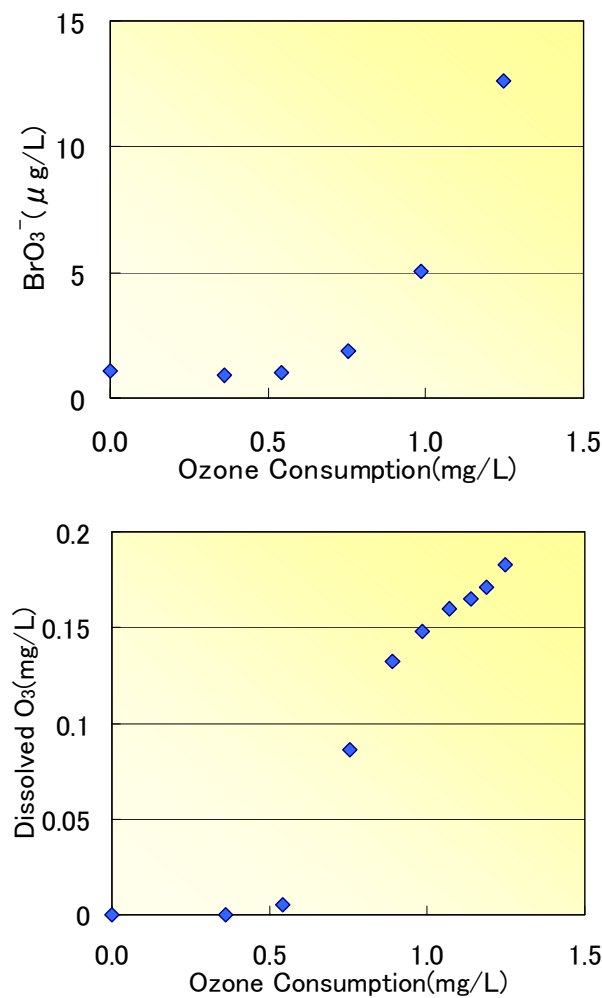

Fig. 5. Bromate formation (Tama River) bromide ion concentration: $150 \mu \mathrm{g} / \mathrm{L}$, DOC: $1.3 \mathrm{mg} / \mathrm{L}$
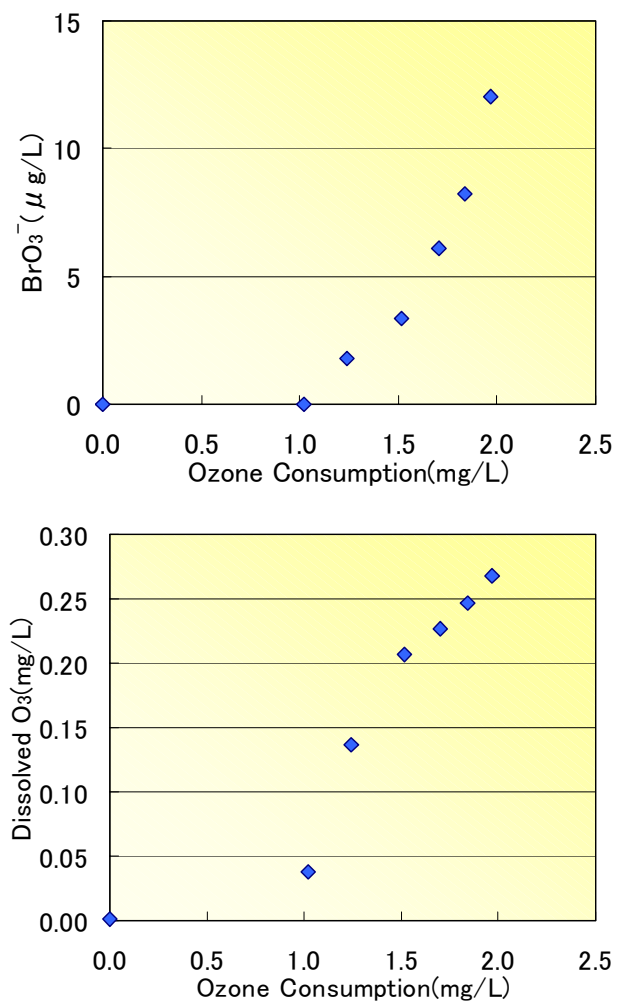

Fig. 6. Bromate formation (Edo River) bromide ion concentration: $66 \mu \mathrm{g} / \mathrm{L}$, DOC: $1.0 \mathrm{mg} / \mathrm{L}$ 


\section{CONCLUSION}

This paper has so far presented the current status of ozonizers and ozone treatment technologies. For the ozonizer, its discharge gap can now be narrowed by means of material oxygen to increase ozone concentrations to $300 \mathrm{~g} / \mathrm{Nm}^{3}$. However, to avoid incomplete combustion and ensure safe operating conditions, ozone concentrations must be $150 \mathrm{~g} / \mathrm{Nm}^{3}$ or less.

For ozonation technologies, the present report demonstrates that ozonation is effective in removing taste and odor and reducing trihalomethane and that, to suppress bromate generation, concentrations of dissolved ozone need to be maintained at $0.1 \mathrm{mg} / \mathrm{L}$ or less.

To further widen and establish ozonation will require basic research at demonstrative plants that utilize ozonation techniques capable of handling raw water from waterworks which are becoming increasingly complex in composition.

\section{REFERENCES}

Sato, C. (2002). The Advanced Water Treatment at Kanamachi Purification Plant of Tokyo Metropolitan Goverment Using Edo River as Water Source. Proceeding of $11^{\text {th }}$ Japan/Korea Symposium on Water Environment 2002.121-130.

Ishioka, H.(2002). The Study of High Concentration and High Efficiency Ozone Generator. Thesis. (Saga University)

Mizutani, T., Matsui, H., Kai, K.,Ishioka, H., Miyake, A. and Ogawa, T.(1999). Properties of decomposing Explosion Pressere and flame Propagation behavior of Ozone/Oxygen Mixtures. Proc. $1^{\text {th }}$ Conf.of Korea/Japan Safety Engineering Society.

Morioka, T., Motoyama, N., Hoshikawa, H., Murakami, A., Okada, M. and Moniwa, T. (1993). Kinetic Analysis On The Effects Of Dissolved Inorganic And Organic Substances In Raw Water On The Ozonation Of Geosmin And 2-MIB. OZONE SCIENCE \& ENGINEERING $15,1-18$.

Morioka, T. (2001) The Study on the Application of Ozonation for the Removal of the Taste and Odor-Causing Substances in Water Supply. Thesis. (Hokkaido university)

Kato, Y., Morioka, T., Hoshikawa, H., Okada. M. and Moniwa. T. ( 2002). Bromate formation Minimization and Biodegradability of Dissolved Organic Substances during Ozonation. Proc. IOA Conference : Advances in Ozone Science and Engineering.15-16 April 2002. H.K.

Morioka, T., Motoyama, N., Hoshikawa, H., Murakami, A., Okada, M. and Moniwa,T.(1994). Reaction Kinetics on Auto-decomposition of Ozone by Extended SBH Model. Journal of Japan Water Works Association. 63, 28-40.

Von, Gunten, U. and Hoigne, J. (1994). Bromate Formation During Ozonation of Bromide-Containing Waters : Interaction of Ozone and Hydroxylradical Reactions. Environ. Sci. Tech 28, 1234-1242.

Von, Gunten, U. and Oliveras, T. (1998). Advanced Oxidation of Bromide Containing Waters : Bromate Formation Mechanisms. Environ. Sci. Tech 32, 63-70. 